\title{
Effect of Synthesis Procedures on Physical and Electrochemical Properties of Carbon Supported Pt/Ru Nanophase Electrocatalyst for Fuel Cell Applications
}

\author{
Bhajan Lal ${ }^{1, *}$, Ammarah Kanwal ${ }^{2}$, Safdar Ali ${ }^{1}$, Shafiq Ullah ${ }^{4}$, Amin Badshah $^{3}$, Ataf Ali Altaf ${ }^{3}$, \\ Fiaz Ahmed ${ }^{4}$, Ramsha Raza ${ }^{4}$ \\ ${ }^{1}$ Faculty of Engineering, Sukkur Institute of Business Administration, Sukkur, 65200, Pakistan \\ ${ }^{2}$ Glass \& Ceramics Research Centre, Pakistan Council of Scientific and Industrial Research \\ Laboratories, Ferozepur Road, Lahore, 54000, Pakistan \\ ${ }^{3}$ Department of Chemistry, Quaid-i-Azam University, 45320, Islamabad \\ ${ }^{4}$ National Development Complex, P.O.Box \# 2216, Islamabad \\ *E-mail: bhajan.lal@iba-suk.edu.pk
}

doi: $10.20964 / 2017.02 .12$

Received: 27 September 2016 / Accepted: 23 November 2016 / Published: 30 December 2016

The carbon supported $\mathrm{Pt} / \mathrm{Ru}$ is found be most commercially used anodic electrocatalyst for direct methanol fuel cell applications however, there are ternary and quaternary metallic based catalyst also available. Here we report in outcome of the synthetic procedures on properties of carbon supported $\mathrm{Pt} / \mathrm{Ru}$ catalysts. Different electrocatalysts were synthesized by using propylene glycol, ethylene glycol, glycerin, polyvynilpyrrolidone (PVP) ethylene glycol methodology, hydrazine, sodium borohydride, formic acid, sodium formate as reducing agents and electrochemical reduction of metals on carbon supported electrode. The synthesized electrocatalysts were characterized by; powder XRD, electron microscopic techniques like SEM, EDS, and TEM, Brunauer-Emmett-Teller (BET) for surface area analysis, and finally electrochemical discharge testing (EDT) was carried out to examine performance and durability of synthesized electrocatalyst (open circuit and on load voltages, current density and power density). The synthesized catalysts had shown high catalytic activity and CO tolerance in direct methanol fuel cell applications, higher activity is achieved by those electrocatalysts which are synthesized by using weak reducing agents as examined by electrochemical discharge testing methodology.

Keywords: Direct Methanol Fuel Cell, Pt-Ru electrocatalyst, Carbon black, Electrochemical Discharge Testing 
(C) 2017 The Authors. Published by ESG (www.electrochemsci.org). This article is an open access article distributed under the terms and conditions of the Creative Commons Attribution license (http://creativecommons.org/licenses/by/4.0/). 